\section{Effect of Forward Speed on Hill Dropping Uniformity of a Precision Vacuum Seeder}

\author{
Davut Karayel ${ }^{1}$ and \\ Aziz Özmerzi
}

ADDITIONAL INDEX wORDs. seeding, hill dropping, seed metering, precision seeder, seeding uniformity

\begin{abstract}
Summary. The purpose of this research was to examine the effects of different forward speeds of hill dropping melon (Cucumis melo) and watermelon (Citrullus lanatus) seeds with reference to hill dropping uniformity. For this purpose, melon and watermelon seeds were hill dropped with three different seed plates at the forward speeds of $0.5,1.0,1.5$, and $2.0 \mathrm{~m} \cdot \mathrm{s}^{-1}(1.64,3.28,4.92$, and 6.56 $\mathrm{ft} / \mathrm{s})$. A precision vacuum seeder unit was used in laboratory tests involving a grease belt test stand. Mean hill distance was not affected by forward speed and seed plates, but mean seed number in hill was affected. In terms of the coefficients of variation of hill distance and seed number in hill, the most suitable forward speed was $\mathbf{0 . 5}$ $\mathrm{m} \cdot \mathrm{s}^{-1}$. The scattering distance ratios of forward speed of 0.5 and $1.0 \mathrm{~m} \cdot \mathrm{s}^{-1}$ were about $20 \%$ to $30 \%$, indicating an acceptable level for hill dropping of melon and watermelon.
\end{abstract}

$\mathrm{P}$ recision seeding has been a major thrust of agricultural engineering research for many years; however, most of the research and development work has dealt with seeders for agronomic crops. Work by agricultural engineers on precision seeders for vegetable and other horticultural crops has been very limited. Much of the research on precision seeding has been based on vacuum metering. Short and Huber (1970) developed a vacuum metering system for cucumber (Cucumis satious) seeds and demonstrated its effectiveness in

$\overline{\text { Akdeniz University, Faculty of Agriculture, Department }}$ of Farm Machinery, 07070, Antalya, Turkey.

${ }^{1}$ To whom reprint requests should be addressed. Tel: +90 242 2274560. E-mail address: dkarayel@akdeniz. edu.tr laboratory. Breece et al. (1981) stated that irregular seed placement in the row is often blamed on the seed metering mechanism, when it is actually caused by the seed placement mechanism. Bracy et al. (1999) demonstrated that variability in seed spacing with a precision vacuum seeder decreased with increasing nominal seed spacing, but seed spacing uniformity with a belt seeder was not affected by nominal seed spacing. Parish and Bracy (1998) assessed the uniformity of metering size-graded and ungraded turnip (Brassica rapa var. rapifera) seeds with precision belt and vacuum seeders. Ozmerzi et al. (2002) examined the effects of different seeding depths on precision seeding uniformity of a precision vacuum seeder.

Selection of the appropriate seeding methods depends on many factors, including the soil characteristics, size of seeds, time and labor availability, seeding cost, seeding date opportunity, crop usage, yield goals, and stand establishment risks. Hill dropping places two to six seeds in a group or hill at desired intervals. Number of seeds sown per hill and spacing between hills varies by grower preferences. Direct seeding reduces labor compared to transplanting, but increases the risk involved and requires more management by the producer. Uniform germination and, ultimately, a high percentage of usable transplants are the keys to success with direct seeding. One practical solution to germination problems is hill dropping.

Precision seeders place seeds

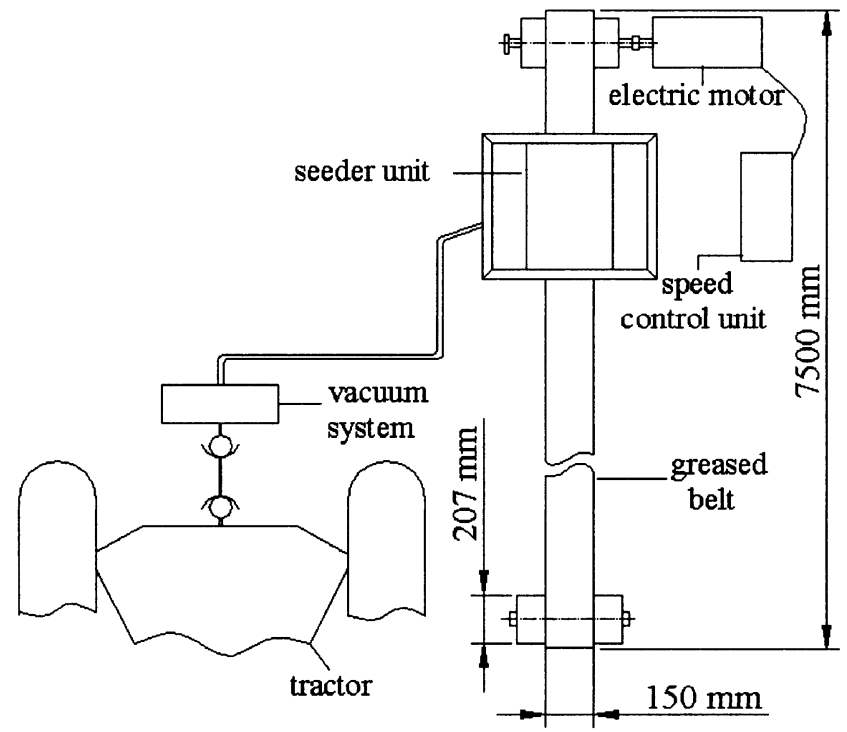

Fig. 1. Schematic view of grease belt test stand as used to determine hill dropping uniformity $(1 \mathrm{~mm}=0.04$ inch $)$. singularly at the required spacing and provide a better growing area per seed. Ryu and Kim (1998) designed a rollertype metering device for precision hill dropping of rice (Oryza sativa). Karayel and Özmerzi (2002) assessed the use of a precision vacuum seeder for hill dropping of some vegetable seeds.

Seed leaving the metering mechanism of a seeder typically contains velocity components in the vertical direction and the horizontal direction parallel to the seeder traveling position. The horizontal velocity component results from the combination of the seeder forward speed (travel), and any horizontal velocity the seeder exerts on the seed relative to the seeder. As the seeder forward speed is usually greater than any relative horizontal velocity imparted to the seed by the seeder (typically rearward), the result is a net horizontal velocity component in the direction of seeder travel. This horizontal velocity gives the seed a tendency to move (e.g., bounce and roll) in the direction of seeder travel upon reaching the seed furrow. Increasing forward speed increases the potential for seed to move in the direction of seeder travel, with an accompanying decrease in seed spacing uniformity.

The objective of this research was to determine the effect of forward speed on hill dropping uniformity of a precision vacuum seeder with melon and watermelon seeds.

\section{Materials and methods}

A greased belt test stand was used to determine the hill dropping 
uniformity of each seed plate configuration. This particular test stand had a 150 -mm-wide (5.9 inches) belt with a 7.5 -m-long $(24.61 \mathrm{ft})$ horizontal viewing surface (Fig. 1). The test stand was equipped with an electronic speed control unit to provide a range of belt surface speeds from 0.5 to $2.0 \mathrm{~m} \cdot \mathrm{s}^{-1}$. A seeder row unit was mounted on a greased belt test stand that utilized an adjustable speed drive mechanism to operate the seed metering devices at a known constant speed. Sufficient oil was added to the top surface of the belt to capture seed as it was released from the seeder unit without rolling or bouncing of seed on the belt surface.

A precision vacuum seeder unit was operated in all treatments. The seeder unit was a general purpose seeder designed for row crops. Three different seed plates were used in the metering mechanism to provide hill dropping. All of the seed plates had six hole groups. Seed plate I had two holes, seed plate II had three holes, and seed plate III had four holes in each hole group; they had in total 12, 18, and 24 holes, respectively (Fig. 2). Each of the holes was $2.5 \mathrm{~mm}(0.10 \mathrm{inch})$ in diameter. The diameter of the seed plates was $230 \mathrm{~mm}$ (9.1 inches). The seed plate operated in a vertical plane and required a vacuum of 3.0 to 8.5 $\mathrm{kPa}\left(0.43\right.$ to $\left.1.23 \mathrm{lbf} / \mathrm{inch}^{2}\right)$ to select a seed. Air suction from the holes of the seed plate caused the seed to stick to the holes. The stuck seed was released from the rotating plate with the help of air-cut that was situated over the opener. The absence of suction allowed the seed to be dropped into soil. It had no seed tube, and seed fall height of the seeder was kept low in order to reduce the chance of non-uniform spacing that can occur due to the bouncing of seed, if dropped from a high plane. Seeder unit was set to hill distance of $550 \mathrm{~mm}$ (21.7 inches), as closely to recommend spacing as possible.

The laboratory test procedure involved testing the metering uniformity of each of the seed plates with melon and watermelon seeds. The main dimensions of seeds are given in Table 1. All seeds used in this research were uncoated seed.

The hill dropping uniformity was analyzed using the methods described by Ryu and Kim (1998). The precision vacuum seeder unit was operated over the grease belt test stand at surface speeds (simulating a seeder forward

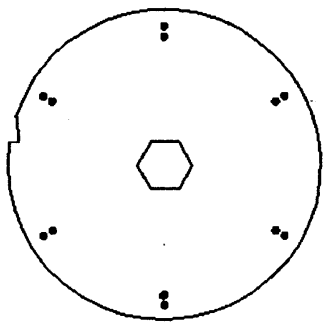

(a) Seed plate I

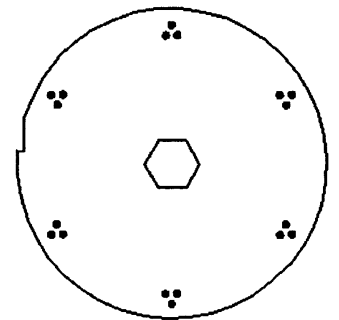

(b) Seed plate II

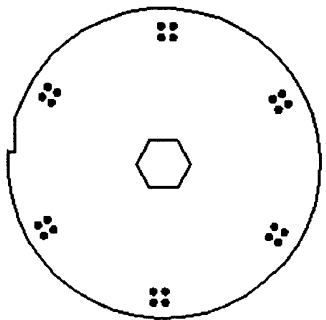

(c) Seed plate III

Fig. 2. The three seed plates as used in the experiment for hill dropping of melon and watermelon seeds.

Table 1. Dimensions of melon and watermelon seeds.

\begin{tabular}{lccc}
\hline Seed & $\begin{array}{c}\text { Length } \\
\text { mm (inch) }\end{array}$ & $\begin{array}{c}\text { Thickness } \\
\text { mm (inch) }\end{array}$ & $\begin{array}{c}\text { Width } \\
\text { mm (inch) }\end{array}$ \\
\hline Melon & $11.2(0.44)$ & $1.9(0.07)$ & $4.2(0.16)$ \\
Watermelon & $8.3(0.33)$ & $2.1(0.08)$ & $6.5(0.26)$ \\
\hline
\end{tabular}

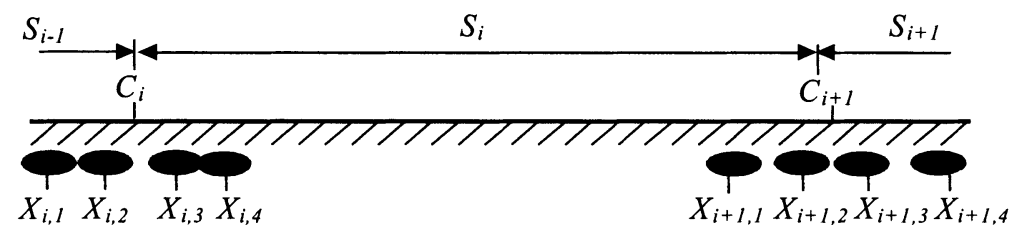

Fig. 3. Placement of seeds in row for hill dropping. The position of each seed is defined by $X_{i, j}$, where $i$ and $j$ indicate the $j$ th seed in the $i$ th hill. The center position of the $i$ th hill is $C_{i}$, and the distance between hills is $S_{i}$ (Ryu and Kim, 1998).

speeds) of $0.5,1.0,1.5$, and 2.0 $\mathrm{m} \cdot \mathrm{s}^{-1}$ and vacuum of $4.0 \mathrm{kPa}(0.58$ $\mathrm{lbf} /$ inch $\left.^{2}\right)$. After seeding the seeds on the test stand, the distance between the seeds was measured over a distance of $7 \mathrm{~m}(23.0 \mathrm{ft})$. The parameters, mean hill distance, coefficient of variation of hill distance, mean seed number in hill, coefficient of variation of seed number in hill, and scattering distance ratio were used to measure and compare seeder unit performance. After hill dropping the seeds on the grease belt, the distances between the seeds were measured. Positions of each seed are defined by $X_{i, j}$ in which subscripts $i$ and $j$ indicate the $j$ th seed in the $i$ th hill as shown in Fig. 3. The center position of the $i$ th hill, $C_{i}$, and hill distance, $S_{i}$, were computed by:

$$
\begin{gathered}
C_{i}=\frac{\sum_{j=1}^{n_{i}} X_{i, j}}{n_{i}} \\
S_{i}=X_{c, i+1}-X_{c, i}
\end{gathered}
$$

where $n$ is the total number of seeds in $i$ th hill.
Dispersion of seeds can be evaluated by the positions of seeds with respect to the hill center. Therefore, position of seeds should be expressed with respect to the hill center. The position of a seed with respect to the hill center, $S P_{i, j}$, was computed by the following equation:

$$
S P_{i, j}=\frac{X_{i, j}-C_{i}}{S_{i}}
$$

Using position of the seed with respect to the hill center, the scattering distance ratio was derived to evaluate the degree of scattering. The scattering distance ratio can be computed by:

$$
\begin{gathered}
R_{s d}=a \cdot \sigma(S P) \cdot 100 \\
\sigma(S P)=\sqrt{\frac{\sum_{t=1}^{m} \sum_{j=1}^{n_{i}}\left(S P_{i, j}\right)^{2}}{\sum_{i=1}^{m} n_{i}}}
\end{gathered}
$$

where $R_{s d}$ is the seed distance ratio, $a$ is the ratio of interval for hill distance to standard deviation of the mean distance between the seed and hill center, 
$\sigma(S P)$ is the standard deviation of the mean distance between the seed and hill center, and $m$ is the total number of hills.

Ryu and Kim (1998) reported that the lower the scattering distance ratio, the better the performance of hill dropping is. A scattering distance ratio of $100 \%$ indicates drill plantings. Scattering distance ratios less than 30\% are known to be good enough for precision hill dropping.

Each experiment was arranged as a randomized complete block, replicated five times. Analysis of variance (ANOVA) was applied to analyze data sets of mean hill distance and mean seed number in hill using the GLM procedure of SAS (Cary, N.C.). Table 2 lists the levels of each parameter in the experiment. Forward speed treatments were the main plot with seed plate being in subplots. Duncan's multiple-range tests were used to identify significantly different means within dependent variables.

\section{Results and discussion}

Effects of forward speed on hill dropping uniformity were analyzed relating to the mean hill distance, coefficient of variation of hill distance, mean seed number in hill, coefficient of variation of seed number in hill, and scattering distance ratio. Mean hill distance and mean seed number in hill were combined for the factorial ANOVA to determine the significant difference in the variability among the parameters. The results of this analysis are given in Table 3 . The differences between the mean hill distances were not significantly influenced by forward speed and seed plate. Analysis of combined data showed significant differences in mean seed number in hill occurring among forward speeds and seed plates. Mean seed number in hill decreased as forward speed increased for hill dropping of watermelon with seed plate III and for hill dropping of melon with seed plates I and III, but the differences between the mean seed number in hill of seed plates I and II for watermelon and seed plate II for melon were not significantly influenced by forward speed (Tables 4 and 5 ). The coefficient of variation of hill distance and seed number in hill increased as forward speed increased with all seed plates for both seeds. The best coefficients of variation of hill distance and hill number in hill were obtained at

Table 2. Number of treatments (levels) and values of experimental parameters of forward speed and seed plates used in the experiment.

\begin{tabular}{lcc}
\hline Class & Levels & \multicolumn{1}{c}{ Values } \\
\hline Forward speed & 4 & $\begin{array}{l}0.5,1.0,1.5, \text { and } 2.0 \mathrm{~m} \cdot \mathrm{s}^{-1} \\
(1.64,3.28,4.92 \text { and } 6.56 \mathrm{ft} / \mathrm{s})\end{array}$ \\
Seed plate & 3 & \begin{tabular}{l} 
Seed plate I, II, and III \\
\hline
\end{tabular}
\end{tabular}

Table 3. Analysis of variance of hill dropping uniformity parameters (mean hill distance and mean seed number in hill) for forward speeds $[0.5,1.0,1.5$, and $2.0 \mathrm{~m} \cdot \mathrm{s}^{-1}(1.64,3.28,4.92$, and $\left.6.56 \mathrm{ft} / \mathrm{s})\right]$ and seed plates (I, II, and III).

\begin{tabular}{|c|c|c|c|c|}
\hline \multirow[b]{2}{*}{ Source } & \multicolumn{2}{|c|}{ Melon } & \multicolumn{2}{|c|}{ Watermelon } \\
\hline & $\begin{array}{c}\text { Mean hill } \\
\text { distance }\end{array}$ & $\begin{array}{c}\text { Mean seed } \\
\text { no. in hill }\end{array}$ & $\begin{array}{c}\text { Mean hill } \\
\text { distance }\end{array}$ & $\begin{array}{c}\text { Mean seed } \\
\text { no. in hill }\end{array}$ \\
\hline & \multicolumn{4}{|c|}{ F values } \\
\hline Forward speed (S) & $0.17^{\mathrm{Ns}}$ & $31.97^{* * *}$ & $0.30^{\mathrm{Ns}}$ & $11.28^{* *}$ \\
\hline Seed plate $(\mathrm{P})$ & $2.49^{\mathrm{Ns}}$ & $72.25^{* * *}$ & $2.89^{\mathrm{Ns}}$ & $110.86^{* * *}$ \\
\hline $\mathrm{S} \times \mathrm{P}$ & $1.87^{\mathrm{Ns}}$ & $2.94^{\mathrm{Ns}}$ & $0.69^{\mathrm{Ns}}$ & $2.36^{\mathrm{Ns}}$ \\
\hline
\end{tabular}

Table 4. Hill dropping uniformity of precision vacuum seeder at different forward speeds using watermelon seeds.

\begin{tabular}{lcccc}
\hline $\begin{array}{l}\text { Forward } \\
\text { speed } \\
\text { m.s }\end{array}$ & $\begin{array}{c}\text { Mean hill } \\
\text { distance } \\
\text { mm (inches) }\end{array}$ & $\begin{array}{c}\text { Mean } \\
\text { seed no. } \\
\text { in hill }\end{array}$ & $\begin{array}{c}\text { Cv of hill } \\
\text { distance } \\
(\%)\end{array}$ & $\begin{array}{c}\text { Cv of } \\
\text { seed no. } \\
\text { in hill (\%) }\end{array}$ \\
\hline & & Seed plate $I$ & & \\
$0.5(1.64)$ & $54.0(2.13) \mathrm{a}^{\mathrm{z}}$ & $2.3 \mathrm{a}$ & 7.9 & 31.2 \\
$1.0(3.28)$ & $54.5(2.14) \mathrm{a}$ & $2.5 \mathrm{a}$ & 12.0 & 31.8 \\
$1.5(4.92)$ & $59.0(2.32) \mathrm{a}$ & $2.2 \mathrm{a}$ & 13.4 & 34.1 \\
$2.0(6.56)$ & $58.5(2.30) \mathrm{a}$ & $2.3 \mathrm{a}$ & 17.2 & 37.3 \\
& & Seed plate II & & \\
$0.5(1.64)$ & $62.5(2.46) \mathrm{a}$ & $3.4 \mathrm{a}$ & 8.1 & 24.8 \\
$1.0(3.28)$ & $61.5(2.42) \mathrm{a}$ & $3.3 \mathrm{a}$ & 9.5 & 26.4 \\
$1.5(4.92)$ & $60.5(2.38) \mathrm{a}$ & $3.0 \mathrm{a}$ & 10.1 & 29.5 \\
$2.0(6.56)$ & $58.5(2.30) \mathrm{a}$ & $2.8 \mathrm{a}$ & 13.6 & 34.2 \\
& & Seed plate III & & \\
$0.5(1.64)$ & $65.5(2.58) \mathrm{a}$ & $4.9 \mathrm{a}$ & 6.6 & 18.9 \\
$1.0(3.28)$ & $63.3(2.49) \mathrm{a}$ & $4.5 \mathrm{a}$ & 8.2 & 20.2 \\
$1.5(4.92)$ & $65.1(2.56) \mathrm{a}$ & $3.7 \mathrm{~b}$ & 11.4 & 25.0 \\
$2.0(6.56)$ & $64.7(2.55) \mathrm{a}$ & $3.1 \mathrm{~b}$ & 16.0 & 27.1 \\
\hline
\end{tabular}

${ }^{2}$ Means within a group followed by same letter are not significantly different at $P=0.05$, by Duncan's multiple range test.

the forward speed of $0.5 \mathrm{~m} \cdot \mathrm{s}^{-1}$ for all seed plates, and at seed plate III for all forward speeds.

Loss of uniformity of the hill distance and seed number in hill were probably a combination of several factors. Although not obvious when viewing the vacuum plate during testing, the high speed of the seed plate at the high forward speed could have resulted in irregular misses and multiples of seeds. The results support reports from Wanjura and Hudspeth (1969) and Bracy et al. (1999), who found that the pattern efficiency of vacuum plates differed most at faster plate speeds.
According to mean seed number in hill, seed plate I can be advised for hill dropping of $2-3$ seeds for watermelon and 2-4 seeds for melon, seed plate II for hill dropping of 3-4 seeds for melon and watermelon, and seed plate III for hill dropping of 4-5 seeds for melon and watermelon at the forward speed of 0.5 and $1.0 \mathrm{~m} \cdot \mathrm{s}^{-1}$.

Scattering distance ratio of forward speed of 0.5 and $1.0 \mathrm{~m} \cdot \mathrm{s}^{-1}$ was 20 to $30 \%$, sufficient for hill dropping of melon and watermelon, while that of the 1.5 and $2.0 \mathrm{~m} \cdot \mathrm{s}^{-1}$ speed was $40 \%$ to $65 \%$, indicating a non-uniform distribution of seeds for hill dropping 
Table 5. Hill dropping uniformity of precision vacuum seeder at different forward speeds using melon seeds.

\begin{tabular}{lcccc}
\hline $\begin{array}{l}\text { Forward } \\
\text { speed } \\
\left.\mathbf{m}^{-1} \mathbf{( f t / s}\right)\end{array}$ & $\begin{array}{c}\text { Mean hill } \\
\text { distance } \\
\text { mm (inches) }\end{array}$ & $\begin{array}{c}\text { Mean } \\
\text { seed no. } \\
\text { in hill }\end{array}$ & $\begin{array}{c}\text { CV of hill } \\
\text { distance } \\
\mathbf{( \% )}\end{array}$ & $\begin{array}{c}\text { CV of } \\
\text { seed no. } \\
\text { in hill (\%) }\end{array}$ \\
\hline & & Seed plate $I$ & & \\
$0.5(1.64)$ & $59.5(2.34) \mathrm{a}^{\mathrm{z}}$ & $3.6 \mathrm{a}$ & 12.9 & 29.3 \\
$1.0(3.28)$ & $60.4(2.38) \mathrm{a}$ & $2.7 \mathrm{~b}$ & 15.0 & 30.2 \\
$1.5(4.92)$ & $58.5(2.30) \mathrm{a}$ & $2.4 \mathrm{~b}$ & 16.4 & 32.9 \\
$2.0(6.56)$ & $60.1(2.36) \mathrm{a}$ & $2.0 \mathrm{~b}$ & 19.3 & 34.5 \\
& & Seed plate II & & \\
$0.5(1.64)$ & $60.0(2.36) \mathrm{a}$ & $3.3 \mathrm{a}$ & 8.4 & 23.5 \\
$1.0(3.28)$ & $60.4(2.38) \mathrm{a}$ & $3.2 \mathrm{a}$ & 10.5 & 25.1 \\
$1.5(4.92)$ & $64.2(2.53) \mathrm{a}$ & $2.9 \mathrm{a}$ & 11.9 & 27.3 \\
$2.0(6.56)$ & $58.5(2.30) \mathrm{a}$ & $2.7 \mathrm{a}$ & 13.0 & 33.2 \\
& & Seed plate III & & \\
$0.5(1.64)$ & $62.1(2.44) \mathrm{a}$ & $5.0 \mathrm{a}$ & 6.6 & 22.0 \\
$1.0(3.28)$ & $61.5(2.42) \mathrm{a}$ & $4.0 \mathrm{~b}$ & 8.4 & 24.6 \\
$1.5(4.92)$ & $61.3(2.41) \mathrm{a}$ & $3.6 \mathrm{~b}$ & 13.2 & 29.5 \\
$2.0(6.56)$ & $63.7(2.51) \mathrm{a}$ & $3.3 \mathrm{~b}$ & 15.7 & 37.1 \\
\hline
\end{tabular}

${ }^{2}$ Means within a group followed by same letter are not significantly different at $P=0.05$, by Duncan's multiple range test.

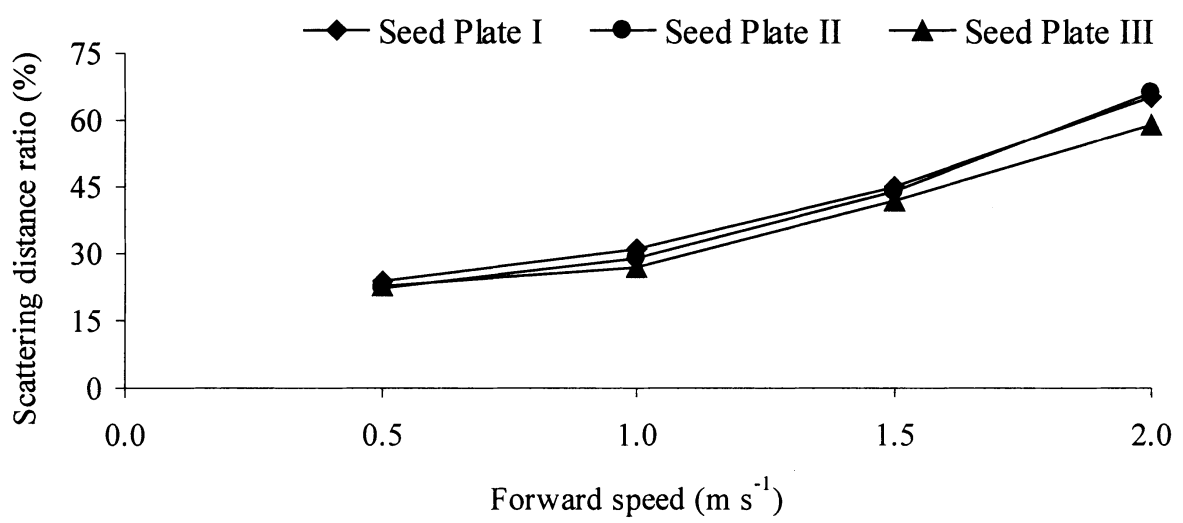

Fig. 4. Scattering distance ratios of the precision vacuum seeder with three different types of seed plates for watermelon seeds $\left(1 \mathrm{~m} \cdot \mathrm{s}^{-1}=3.28 \mathrm{ft} / \mathrm{s}\right)$.

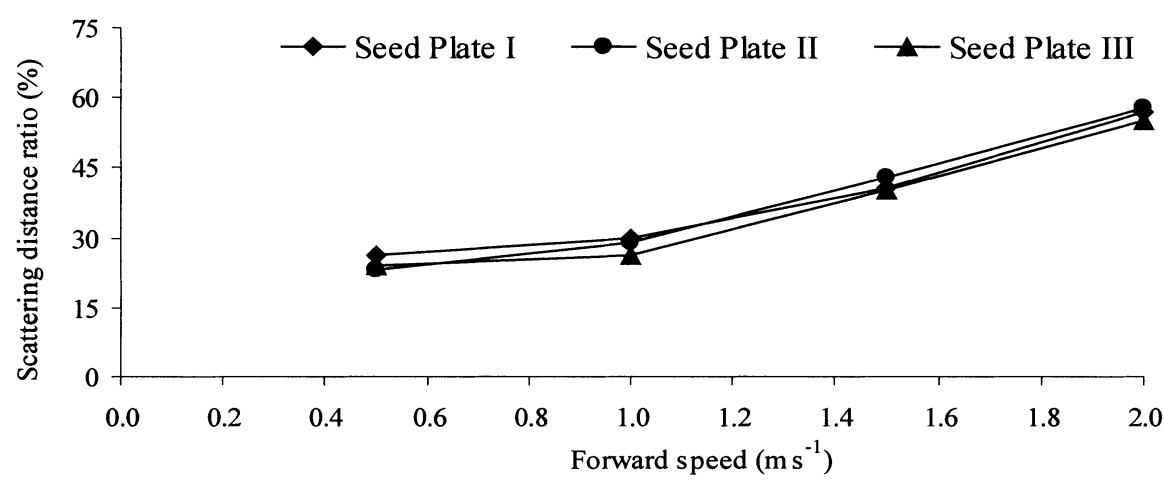

Fig. 5. Scattering distance ratios of the precision vacuum seeder with three different types of seed plates for melon seeds $\left(1 \mathrm{~m} \cdot \mathrm{s}^{-1}=3.28 \mathrm{ft} / \mathrm{s}\right)$.
(Figs. 4 and 5 ). Since scattering distance ratio of the vacuum seeder was poorer at the faster forward speeds, the effect of seed drop should be considered a factor. The faster forward speeds resulted in irregular falling velocities and trajectories of the seeds. Increasing forward speed increased the potential for seed to move in direction of seeder travel, with an accompanying decrease in hill distance uniformity and increase in scattering distance ratio.

\section{Conclusions}

On the basis of this research we reached the following conclusions. Mean hill distance was not affected by forward speed and seed plates, but the mean seed number in hill was affected. The coefficients of variation of hill distance and seed number in hill increased as forward speed increased for both seeds. The scattering distance ratios for forward speeds of 0.5 and $1.0 \mathrm{~m} \cdot \mathrm{s}^{-1}$ were about $20 \%$ to $30 \%$, the range that the authors consider adequate for hill dropping of melon and watermelon.

\section{Literature cited}

Bracy, R.P., R.L. Parish, and J.E. McCoy. 1999. Precision seeder uniformity varies with theoretical spacing. HortTechnology 9(1):47-50

Breece, H.E., H.V. Hansen, and T.A. Hoerner. 1981. Planting. Fundamentals of machine operation series, Deere and Co., Moline, Ill. p. 34-37.

Karayel, D. and A. Özmerzi. 2002. A research on the use of a precision vacuum seeder unit for hill drop sowing. 8th Intl. Cong. on Mech. and Energy in Agr. IzmirTurkey, 15-17 Sept.

Özmerzi, A., D. Karayel, and M. Topakci. 2002. Effect of sowing depth on precision seeder uniformity. Biosystems Eng. 82(2):227-230.

Parish, R.L. and R.P. Bracy. 1998. Metering nonuniform vegetable seed. HortTechnology 8(1):69-71.

Ryu, I.H. and K.U. Kim. 1998. Design of roller type metering device for precision planting. Trans. Amer. Soc. Agr. Eng. 41(4):923-930.

Short, T.H. and S.G. Huber. 1970. The development of a planetary-vacuum seed metering device. Trans. Amer. Soc. Agr. Eng. 13(6):803-805.

Wanjura, D.F. and E.B. Hudspeth. 1969. Performance of vacuum wheels metering individual cottonseed. Trans. Amer. Soc. Agr. Eng. 12(6):775-777. 